\title{
BEBAN CAREGIVER DAN STRES KELUARGA PASIEN STROKE
}

\author{
Arnika Dwi Asti*, Shynta Novariananda, Tri Sumarsih
}

Universitas Muhammadiyah Gombong,

*e-mail: arnikadwiasti@gmail.com

\begin{tabular}{|c|c|}
\hline & Abstract \\
\hline $\begin{array}{l}\text { Keywords: } \\
\text { beban caregiver, } \\
\text { stress, stroke }\end{array}$ & $\begin{array}{l}\text { Prevalensi stroke meningkat setiap tahunnya. Pasien stroke mengalami } \\
\text { kelumpuhan anggota tubuh yang menyebabkan perubahan dan penurunan } \\
\text { fungsi kehidupan fisik dan psikologis. Kondisi ini membuat pasien stroke } \\
\text { membutuhkan bantuan orang lain dalam aktivitas sehari-hari. Oleh } \\
\text { karena itu, salah satu anggota keluarga sebagai unit terdekat pasien akan } \\
\text { berperan sebagai caregiver yang membantu memenuhi kebutuhan pasien } \\
\text { stroke. Caregiver sendiri juga memiliki orientasi pemenuhan kebutuhan, } \\
\text { perawatan dan pikiran untuk diri sendiri. Pengabaian pemenuhan } \\
\text { kebutuhan ini dapat mengakibatkan stres fisik dan mental pada caregiver. } \\
\text { Penelitian ini bertujuan untuk mengidentifikasi hubungan beban } \\
\text { caregiver dengan stres keluarga pada pasien stroke. Ini merupakan } \\
\text { penelitian deskriptif kuantitatif dengan pendekatan cross-sectional. } \\
\text { Penelitian dilakukan di RS PKU Muhammadiyah Gombong. Sejumlah } \\
\text { 122 orang caregiver utama diambil sebagai responden penelitian dengan } \\
\text { tehnik consecutive sampling. Data dianalisa menggunakan Chi-square. } \\
\text { Hasil penelitian menunjukkan sebagian besar responden berada pada } \\
\text { rentang beban sedang sebanyak } 63 \text { orang (51,64 \%) dan tingkat stres } \\
\text { sedang sebanyak } 60 \text { orang (49,18\%). Uji korelasi chi-square } \\
\text { menunjukkan nilai p value 0,035 < 0,05 sehingga dinyatakan terdapat } \\
\text { hubungan antara beban caregiver dengan tingkat stres keluarga pada } \\
\text { pasien stroke. Semakin tinggi beban caregiver maka tingkat stres yang } \\
\text { dirasakan juga semakin tinggi. Penting bagi perawat jiwa untuk } \\
\text { mengetahui mengenai beban caregiver dan stres yang dirasakan sehingga } \\
\text { dapat membantu melalui program manajemen stres bagi caregiver pasien } \\
\text { stroke. }\end{array}$ \\
\hline
\end{tabular}

\section{PENDAHULUAN}

Stroke merupakan salah satu penyebab kematian terbesar di benua Asia dan penyebab perubahan gaya hidup yang signifikan pada pasiennya terkait dengan mobilitas pasien, pola emosi, tingkah laku, serta kemampuan komunikasi. Prevalensi stroke di Indonesia rata-rata sebesar 10,9\% permil. Provinsi Jawa Tengah memiliki prevalensi stroke terbesar keempat dengan jumlah 11\% per mil pada tahun 2018.
Angka kejadian stroke dipengaruhi oleh beberapa faktor risiko seperti : merokok, minum-minuman beralkhohol, diet atau pola makan, gaya hidup, obesitas, obatobatan, dan riwayat keluarga/keturunan (Riskesdas, 2018).

Pasien stroke mengalami kelumpuhan anggota tubuh, gangguan bicara, proses berpikir, daya ingat dan bentuk kecacatan lainnya, biasanya disebabkan oleh gangguan fungsi otak. 
Terdapat perubahan dan penurunan fungsi kehidupan baik fisik dan psikologis dapat membuat penderita stroke merasa rendah diri, malu dan merasa tidak berdaya. Kondisi yang dialami pasien stroke membuat pasien stroke membutuhkan bantuan orang lain. Penderita stroke tidak hanya membutuhkan bantuan fisik, tetapi juga bantuan psikologis dan spiritual agar dapat menerima kondisinya dan menjalani kehidupan. Oleh karena itu, seseorang perlu membantu dan merawatnya sebagai caregiver. Peran keluarga sebagai caregiver bagi proses pengobatan pasien stroke, berpotensi menimbulkan stress dan beban caregiver (Fadilah et al., 2019).

Pemberian bantuan dan perawatan kepada penderita stroke membutuhkan banyaknya alokasi waktu, pikiran, tenaga dan emosi caregiver. Caregiver sendiri juga memiliki orientasi pemenuhan kebutuhan, perawatan dan pikiran untuk diri sendiri. Pengabaian pemenuhan kebutuhannya dapat mengakibatkan stres fisik dan mental pada caregiver. Terjadi perubahan kesehatan emosional, kesehatan fisik dan stres pada caregiver dalam merawat keluarga yang sakit kronik dalam jangka waktu yang lama. Kesulitan dan ketidakmampuan caregiver untuk mengatasi dan menyelesaikan kesulitan dan tekanan yang muncul saat melakukan tugas caregiver dapat menjadi beban dan tekanan. Beban dan tekanan yang ditimbulkan membuat caregiver merasa stres, cemas bahkan depresi (Zhu \& Jiang, 2018). Banyak penelitian yang berorientasi pada angka depresi pasien stroke sementara perhatian terhadap depresi caregiver sangat sedikit (Hultman et al., 2019).
Berdasarkan hasil studi pendahuluan terhadap 10 caregiver utama keluarga yang sedang merawat pasien stroke di Rumah Sakit PKU Muhammadiyah Gombong, 5 responden mengatakan stress karena banyak kendala dalam merawat pasien stroke, 3 responden mengatakan mengalami kelelahan fisik, gelisah, cemas, merasa marah, kurangnya waktu untuk bersama keluarga inti, dan mengurusi pembiayaan rumah sakit yang mahal. Terdapat 7 responden yang mengatakan merasa terbebani dengan kondisi anggota keluarga yang membuatnya tidak ada waktu untuk melakukan aktivitas seperti biasa setiap harinya seperti bekerja, waktu bersama keluarga, tanggung jawab yang berat, dan perekonomian yang menurun.

Penelitian ini bertujuan untuk mengetahui gambaran stress dan beban caregiver yang dialami oleh keluarga dengan pasien stroke dan menganalisa hubungan kedua variabel tersebut.

\section{METODE}

Ini merupakan penelitian deskriptif kuantitatif dengan metode korelasi dan pendekatan cross sectional. Penelitian dilakukan di 3 ruang rawat inap dan poli rawat jalan penyakit dalam RS PKU Muhammadiyah Gombong selama bulan Januari - Februari 2021. Sebanyak 122 responden diambil dengan tehnik consecutive sampling, dengan kriteria inklusi merupakan caregiver utama pasien stroke, berusia 18-50 tahun dan tidak mengalami gangguan jiwa. Beban caregiver diukur dengan menggunakan kuesioner Zarit Burden Interview (ZBI) sedangkan stress diukur dengan menggunakan kuesioner Depression Anxiety and Stress Scale (DASS). 


\section{HASIL}

Barikut adalah tabel 1. Karakteristik caregiver keluarga pasien stroke di RS PKU Muhammadiyah Gombong $(\mathrm{n}=122)$

\begin{tabular}{clrr}
\hline No & \multicolumn{1}{c}{ Karakteristik } & Frekuensi & Persentase (\%) \\
\hline 1 & Umur & & \\
& $\leq 25$ Tahun & 16 & 13.1 \\
& 26-45 Tahun & 69 & 56.6 \\
& 266 Tahun & 37 & 30.3 \\
& Total & 122 & 100 \\
\hline 2 & Jenis Kelamin & & \\
& Laki-Laki & 39 & 32,0 \\
& Perempuan & 83 & 68,0 \\
& Total & 122 & 100 \\
\hline 3 & Tingkat Pendidikan & & \\
& SD & 27 & 22,1 \\
& SMP & 46 & 37,7 \\
& SMA & 37 & 30,3 \\
& D3 & 5 & 4,1 \\
& S1 & 7 & 5,7 \\
& Total & 122 & 100 \\
\hline 4 & Pekerjaan & & \\
& Swasta & 46 & 37,7 \\
& IRT & 65 & 53,3 \\
& Perawat & 6 & 4,9 \\
& Guru & 3 & 2,5 \\
& Bidan & 2 & 1,6 \\
& Total & 122 & 100 \\
\hline
\end{tabular}

Berdasarkan tabel 1 dapat diketahui bahwa caregiver keluarga pasien stroke mayoritas berusia 26-45 tahun sebesar 56,60\% (69 orang), berjenis kelamin perempuan sebesar $68 \%$ (83 orang), berpendidikan SMP sebesar 37,7\% (46 orang) dan mempunyai pekerjaan IRT sebesar $53,3 \%$ (65 orang).

Berikut adalah tabel 2. Distribusi frekuensi beban caregiver dan stres keluarga pasien stroke di RS PKU Muhammadiyah Gombong ( $\mathrm{n}=122)$

\begin{tabular}{ccccc}
\hline No & Interval & Kategori & Frekuensi & Persentase $(\%)$ \\
\hline 1 & Beban caregiver & & & \\
& $61-88$ & Beban Berat & 52 & 42,62 \\
& $41-60$ & Beban Sedang & 63 & 51,64 \\
$21-40$ & Beban Ringan & 6 & 4,92 \\
& $0-20$ & Tidak Ada Beban & 1 & 0,82 \\
& Total & 122 & 100 \\
\hline 2 & Tingkat Stres & Stres Sangat Berat & 1 & 0,82 \\
& $\geq 34$ & Stres Berat & 47 & 38,52 \\
& $26-33$ & Stres Sedang & 60 & 49,18 \\
& $19-25$ & Stres Ringan & 11 & 9,02 \\
& $15-18$ & Normal & 3 & 2,46 \\
$0-14$ & Total & 122 & 100 \\
\hline
\end{tabular}

Berdasarkan tabel 2 terlihat bahwa mayoritas beban caregiver keluarga pasien stroke berada pada kategori beban sedang sebesar 51,64\% (63 orang) dan mayoritas berada pada kategori stres sedang sebesar 49,18\% (60 orang). 
Berikut adalah tabel 3. Hasil Analisis Chi Square Hubungan Beban Caregiver terhadap Tingkat Stres Keluarga Pasien Stroke di RS PKU Muhammadiyah Gombong ( $\mathrm{n}=122)$

\begin{tabular}{|c|c|c|c|c|c|c|}
\hline \multicolumn{7}{|c|}{ Tingkat Stres } \\
\hline Beban Caregiver & Normal & $\begin{array}{l}\text { Stres } \\
\text { ringan }\end{array}$ & $\begin{array}{c}\text { Stres } \\
\text { sedang }\end{array}$ & $\begin{array}{l}\text { Stres } \\
\text { berat }\end{array}$ & $\begin{array}{c}\text { Stres } \\
\text { sangat berat }\end{array}$ & $p$ value \\
\hline Tidak ada beban & 0 & 0 & 1 & 0 & 0 & \\
\hline Beban ringan & 0 & 1 & 4 & 1 & 0 & \\
\hline Beban sedang & 1 & 6 & 43 & 15 & 0 & 0,035 \\
\hline Beban berat & 2 & 4 & 14 & 29 & 1 & \\
\hline Total & 3 & 11 & 62 & 45 & 1 & \\
\hline
\end{tabular}

Berdasarkan tabel 3 terlihat setelah dilakukan uji chi-square dengan taraf signifikan 5\% $(0,05)$ diperoleh bahwa $p$ value $=0,035$ yang berarti signifikan $<0,05$, sehingga dapat disimpulkan bahwa terdapat hubungan antara beban caregiver dengan tingkat stres keluarga pasien stroke di RS PKU Muhammadiyah Gombong.

\section{PEMBAHASAN}

Hasil analisis deskriptif menunjukkan bahwa beban caregiver keluarga pasien stroke di RS PKU Muhammadiyah Gombong mayoritas berada pada kategori beban sedang sebesar 51,64\% (63 orang). Beban caregiver ini dirasakan karena sebagian besar caregiver menggunakan waktu produktifnya untuk merawat pasien stroke. Caregiver menyatakan mengalami hambatan dalam kehidupan sosial, kekhawatiran yang terus menerus, mendapat tekanan karena beban dan tanggung jawab serta stres selama merawat anggota keluarga yang stroke (Pahria, Sari dan Lisnawati, 2019). Hasil ini sejalan dengan penelitian dilakukan oleh Ariska Handayani, dan Hartati (2020) dalam merawat anggota keluarga yang mengalami stroke dimana sebanyak $22 \quad(53,7 \%)$ caregiver mengalami beban ringan, $16(39 \%)$ mengalami beban sedang. Faktor yang paling relevan dengan beban caregiver adalah hubungan dekat dengan pasien, jumlah caregiver, waktu menderita stroke dan waktu yang dibutuhkan untuk merawat pasien setiap hari. Beban ini mempengaruhi kesehatan caregiver dan menyebabkan adanya kelelahan, gangguan tidur, kehilangan nafsu makan, sakit kepala, tekanan darah tinggi, maag. Beban caregiver juga mempengaruhi kondisi emosional, antara lain stres, kecemasan dan kekhawatiran terhadap kondisi pasien (Ariska, Handayani, dan Hartati, 2020).

Hasil analisis deskriptif menunjukkan bahwa tingkat stres caregiver pasien stroke
RS PKU Muhammadiyah Gombong mayoritas berada pada kategori stres sedang sebesar 49,18\% (60 orang). Hal ini sesuai dengan penelitian sebelumnya yang menyatakan bahwa 30-40\% caregiver pasien stroke mengalami depresi. (Hultman et al., 2019). Penelitian lain yang dilakukan oleh Pahria, Sari, dan Lisnawati (2019) menyatakan bahwa dari 92 responden sebanyak 66 orang $(71,7 \%)$ mengalami gangguan perasaan yang normal, sebanyak 19 orang $(20,7 \%)$ mengalami gangguan perasaan yang ringan. Sementara itu 4 orang $(4,3 \%)$ mengalami stres yang ringan, 2 orang $(2,2 \%)$ mengalami stres sedang dan 1 orang $(1,1 \%)$ mengalami stres berat. Hal ini mungkin terjadi karena berbagai faktor yaitu karakteristik pekerjaan dan penghasilan. Penelitian lain menyatakan bahwa perubahan psikososial pada caregiver pasien stroke diperngaruhi beberapa hal seperti jenis kelamin, pendidikan, pekerjaan, dan hubungan kekerabatan (Zhu \& Jiang, 2018).

Berdasarkan hasil penelitian menunjukkan bahwa ada hubungan beban caregiver dengan tingkat stres keluarga terhadap pasien stroke di RS PKU Muhammadiyah Gombong, dengan signifikansi $<0,05$. Artinya bahwa beban caregiver yang tinggi, maka tingkat stres yang dirasakan juga semakin tinggi. Hal ini sesuai dengan penelitian sebelumnya yang menyatakan bahwa kecemasan dan depresi merupakan sesuatu yang wajar terjadi pada caregiver pasien stroke dan hal tersebut 
terkait erat dengan beban caregiver yang dirasakan (Hu et al., 2018). Hasil tersebut didukung hasil penelitian Pahria, dkk., (2019) bahwa semakin berat beban keluarga dalam merawat pasien stroke, semakin berat tingkat stresnya. Dalam penelitian ini terbukti bahwa beban caregiver berkorelasi positif dengan gejala stres dan korelasi antar caregiver berada pada level sedang.

\section{SIMPULAN}

Mayoritas beban caregiver keluarga pasien stroke di RS PKU Muhammadiyah Gombong berada pada kategori beban sedang. Tingkat stress yang dirasakan mayoritas berada pada rentang stress sedang. Terdapat hubungan antara beban caregiver dengan tingkat stres keluarga dibuktikan dengan $p$ value $=0,035(œ<0,05$.) Semakin tinggi beban caregiver maka semakin tinggi tingkat stres yang dirasakan. Penting bagi perawat di rumah sakit untuk memperhatikan beban dan tingkat stress caregiver pasien stroke agar dapat membantu mengatasi masalah yang terjadi akibat kedua hal tersebut.

\section{DAFTAR PUSTAKA}

[1] Ariska, Y. N., Handayani, P. A., \& Hartati, E. (2020). Faktor yang Berhubungan dengan Beban Caregiver dalam Merawat Keluarga yang Mengalami Stroke. Holistic Nursing and Health Science, 3(1), 52-63.
[2] Fadilah, N., Kusnanto, Nursalam, \& Rahariyani, L. D. (2019). Analysis of influencing factors of burden of caregiver among stroke patients at home. Journal of Public Health in Africa. https://doi.org/10.4081/jphia.2019.1188

[3] Hu, P., Yang, Q., Kong, L., Hu, L., \& Zeng, L. (2018). Relationship between the anxiety/depression and care burden of the major caregiver of stroke patients. Medicine (United States). https://doi.org/10.1097/MD.00000000000 12638

[4] Hultman, M. T., Everson-Rose, S. A., Tracy, M. F., Lindquist, R., \& Hadidi, N. N. (2019). Associations between characteristics of stroke survivors and caregiver depressive symptoms: a critical review. Topics in Stroke Rehabilitation. https://doi.org/10.1080/10749357.2019.1 641010

[5] Pahria, T., Sari, C. W. M., \& Lisnawati, L. (2019). Hubungan Beban Dengan Depresi pada Keluarga yang Merawat Pasien Stroke. Jurnal Pendidikan Keperawatan Indonesia, 5(2), 157-166.

[6] Zhu, W., \& Jiang, Y. (2018). A Metaanalytic Study of Predictors for Informal Caregiver Burden in Patients With Stroke. Journal of Stroke and Cerebrovascular Diseases.

https://doi.org/10.1016/j.jstrokecerebrova sdis.2018.08.037 